\title{
ANÁLISE DA GEOMETRIA DOS AQUIFEROS COSTEIROS DA PORÇÃO NORTE DA REGIÃO METROPOLITANA DO RECIFE-PE A PARTIR DE PERFIS LITOLÓGICOS DE POÇOS TUBULARES
}

\author{
Leanize Teixeira Oliveira ${ }^{1}$ \\ José Geilson Alves Demetrio ${ }^{2}$ \\ Maria Emília Travassos Rios Tomé ${ }^{3}$ \\ Cleidiane de Lemos Vasconcelos ${ }^{3}$
}

\begin{abstract}
RESUMO
Este trabalho foi desenvolvido após o cadastramento de 570 poços tubulares da porção norte da região metropolitana do Recife, abrangendo os municípios de Paulista, Abreu e Lima, Araçoiaba, Igarassú, Itamaracá, Itaquitinga e Goiana, como parte integrante do Projeto intitulado "Estudo Hidrogeológico da porção Norte da Região Metropolitana do Recife" financiado pela Companhia Pernambucana do Meio Ambiente (CPRH). A partir das informações obtidas dos perfis litológicos-construtivos dos poços, foram elaborados oito perfis geológicos. Os resultados obtidos são de grande importância para a caracterização da geologia regional e demonstra alguns aspectos relevantes quanto à geometria dos aqüiferos. Ressalta-se ainda algumas considerações feitas sobre as dificuldades em utilizar os dados das descrições das amostras de calha feitas pelos profissionais que acompanham a perfuração dos poços, sendo que nem sempre se trata de pessoal devidamente treinado. Contudo, os resultados obtidos foram satisfatórios e apresentam-se coerentes com a bibliografia, tendo sido definidos três sistemas aqüiferos assim denominados: Aqüífero intergranular principal (Formação Beberibe e Itamaracá), Aquifero cárstico (Formação Gramame/Maria Farinha) e Aqüífero Barreiras (Formação Barreiras).
\end{abstract}

\footnotetext{
ABSTRACT

This work was developed after the cadastre of 570 tubular wells of the portion north of the region metropolitan of Recife, having enclosed the cities of Paulista, Abreu eLima, Araçoiaba, Igarassú, Itamaracá, Itaquitinga and Goiana, as integrant part of the intitled Project Estudo Hidrogeológico of the portion North of the Region Metropolitan of Recife financed for the Companhia Pernambucan do Meio Ambiente (CPRH). From the gotten information of the constructive profiles litológicos- of the wells, had been elaborated eight geologic profiles. The gotten results are of great importance for the characterization of regional geology and demonstrate some excellent aspects how much to the geometry of the aqüiferos. One still standes out some considerations made on difficulties in using the data of the descriptions of the samples made by the professionals who follow the perforation of the wells, being that nor always one is about staff duly trained. However, the gotten results had been satisfactory and are presented coherent with the bibliography, having been defined three thus called aqüiferos systems: intergranular main aquifer (Formation Beberibe and Itamaracá), Karst aquifer (Gramame/Maria Farinha) and Barreiras aquifer (Formation Barreiras).

Palavras-Chave - Beberibe, Perfis litológicos, Amostras de calha

${ }^{1}$ Professora do CEFET-BA, Departamento II, Rua Emídio Santos s/n, Barbalho, Salvador - Bahia, Mestranda do PPG em Geociências da UFPE.

2 Professor Adjunto I, UFPE, Departamento de Engenharia de Minas; R. Acadêmico Hélio Ramos, s/n, $4^{\circ}$ andar, Centro de Tecnologia em Geociências, Cidade Universitária; 50740-530;Recife; Pernambuco; Brasil.

${ }^{3}$ Estudante de Graduação do curso de Geologia da UFPE.
} 


\section{INTRODUÇÃO}

A porção norte da região metropolitana do Recife-PE corresponde a uma área de $1383,4 \mathrm{~km}^{2}$, abrangendo os municípios de Goiana, Araçoiaba, Itaquitinga, Itapissuma, Igarassú, Abreu e Lima, Itamaracá e Paulista, cuja população total é de 570.762 habitantes, com $89,65 \%$ do total residindo na zona urbana, (IBGE, 2001). Mananciais hídricos superficiais e subterrâneos são utilizados para o abastecimento público deste contingente humano, devendo-se salientar que nas últimas décadas têm sido freqüentes programas de racionamento de água em função das variações das disponibilidades de águas superficiais, o que acarreta uma crescente descarga de bombeamento a partir das baterias de poços da COMPESA (Companhia Pernambucana de Saneamento) espalhados por toda a região, além de poços de particulares. A figura 1 , apresentada a seguir, demonstra a evolução no tempo da descarga de bombeamento diária efetuada pela COMPESA ao longo dos últimos anos.

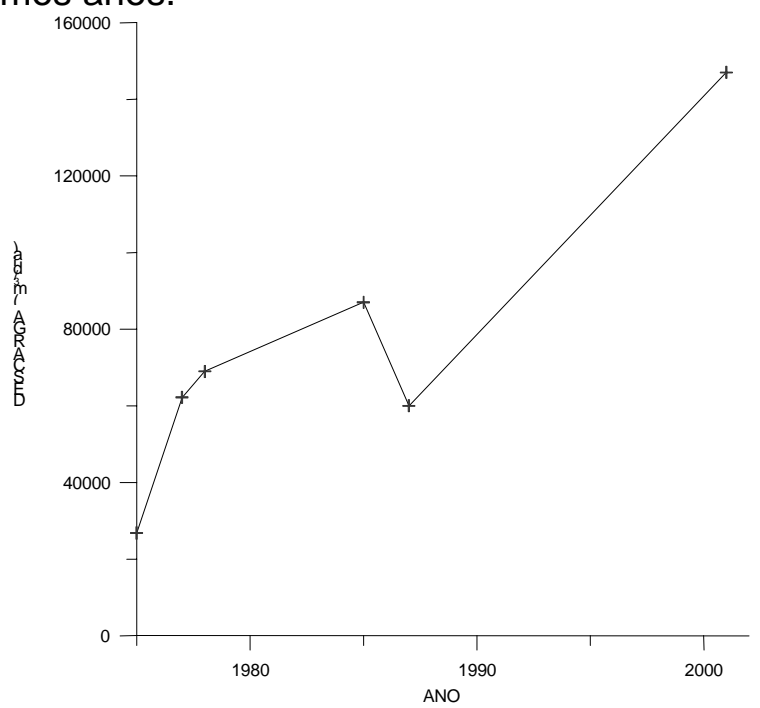

Figura 1. Evolução da descarga de bombeamento diário dos poços de abastecimento público da COMPESA.

Com pode ser observado, as descargas diárias passaram de $26.800 \mathrm{~m}^{3} / \mathrm{dia}$ em 1975 para $147.000 \mathrm{~m}^{3} / \mathrm{dia}$ em 2001, segundo dados publicados nos relatórios da OESA, 1975, COMPESA/CPRM, 1978, FRANÇA, 1987 e DNPM, 2001. Observa-se que a curva é crescente excetuando-se o ano de 1987, quando entra em operação o manancial superficial da barragem de Botafogo. Em função da crescente demanda de água subterrânea, muitos estudos foram realizados visando analisar suas conseqüências, tal como a evolução histórica dos níveis potenciométricos do Aqüífero Beberibe, principal aqüífero da região, e o comportamento da cunha salina, em face da explotação ocorrida, a exemplo dos trabaIhos de FRANÇA et al., 1987, MONTENEGRO et al., 1992, entre outros .

O conhecimento é a peça chave para melhor gerenciar e utilizar racionalmente os recursos hídricos, pois a explotação da água subterrânea feita de forma aleatória e sem planejamento pode ocasionar problemas como a superexploração de aqüíferos e a salinização das águas dos mesmos. A partir de um amplo conhecimento de um aqüífero é possível gerenciar a sua utilização de forma mais racional bem como introduzir medidas mais eficazes para a sua proteção, seja através de modelos de otimização para gerenciamento da água subterrânea ou através da aplicação de medidas de prevenção e controle da poluição de aqüíferos, entre outros. Sabendo-se da necessidade do conhecimento da geologia para possibilitar a caracterização hidrogeológica de uma região, este trabalho tem como objetivo contribuir para o aprimoramento do conhecimento a respeito da geometria dos aqüíferos da região a partir do cadastramento de poços tubulares e análise dos perfis litológicos dos mesmos.

Procura ainda alertar sobre as dificuldades e problemas encontrados na descrição litológica de perfis litológicos-construtivos de poços tubulares, elaborados a partir unicamente da análise das amostras de caIha, pois a quase totalidade dos poços cadastrados não utilizou métodos mais sofisticados, a exemplo do uso de perfis geofísicos.

Este trabalho foi possível graças ao contrato firmado entre a CPRH e a FADE Fundação de Apoio ao Desenvolvimento da UFPE /LABHID (Laboratório de Hidrogeologia - CTG/UFPE) para desenvolvimento do projeto "Estudo Hidrogeológico da porção Norte da Região Metropolitana do Recife".

\section{CADASTRAMENTO DOS POÇOS}

Foram cadastrados 540 poços localizados na área de estudo, ver figura $2 \mathrm{em}$ anexo, a partir das seguintes fontes: Poços de abastecimento público da COMPESA, em operação e desativados; Cadastro de poços do banco de dados da Companhia de Pesquisa de Recursos Minerais (CPRM) - 
SIAGAS; Poços em processo de licenciamento ambiental e pedido de outorga da $\mathrm{CPRH} / \mathrm{SRH}$ (Secretaria de Recursos Hídricos do Estado de Pernambuco); Banco de dados do Projeto Hidrorec (COSTA et al.,1998) e Poços de produção de água mineral, registrados no DNPM para pedido de pesquisa e lavra. Também foram utilizadas informações de poços de sondagem dos projetos de dimensionamento de jazidas de calcário da Ilha de Itamaracá e fosfato de Pernambuco, visando complementar o banco de dados principalmente nas áreas onde havia lacunas.

Apesar de serem cadastrados 540 poços tubulares, apenas 390 estão sendo utilizados efetivamente na pesquisa, devido aos seguintes fatores que ocorreram individual ou simultaneamente: ausência de coordenadas; possibilidade de duplicidade de informações, como vários poços distintos com a mesma coordenada; poços que não apresentavam fichas de poço, com informações relevantes para o estudo; poços considerados não confiáveis em função da ocorrência de informações truncadas; poços com coordenadas comprovadamente erradas, como alguns poços que se situavam no Oceano Atlântico.

Os bancos de dados utilizados neste estudo por vezes apresentam deficiências e informações que se sobrepõem, como por exemplo: 1) Poços cadastrados no Inventário Hidrogeológico podem estar cadastrados no Hidrorec com outra denominação; 2) Alguns poços produtores de água mineral podem estar cadastrados em outro(s) banco(s) de dado(s) com outra denominação; 3) O banco de dados que se apresentou mais deficiente foi o da CPRM, denominado SIAGAS, tendo sido encontrados diversos problemas, como inconsistência de dados, poços iguais cadastrados com números distintos, entre outros. Deve-se salientar que não foram feitas checagens no campo dos poços cadastrados.

Após o criterioso refinamento e filtragem dos dados a serem utilizados fez-se a plotagem dos poços em uma base cartográfica em meio digital, gentilmente cedida pela $\mathrm{CPRH}$, ver figura $3 \mathrm{em}$ anexo.

\section{GEOLOGIA REGIONAL}

A área de estudo está inserida na Bacia sedimentar costeira denominada Pernambuco-Paraíba, que se estende entre as
Bacias de Sergipe-Alagoas e Potiguar. Por tratar-se de uma bacia com estrutura homoclinal, diz-se que a mesma corresponde a um "conjunto de acumulações sedimentares em estruturas tectônicas deprimidas", não sendo portanto uma bacia única e homogênea (MABESONE, 1991).

Baseado em dados estruturais e geofísicos, segundo Fortes, 1986, nos terrenos cristalinos da Bacia Potiguar e da Bacia PEPB a norte de Recife, encontram-se grandes falhas de direção NE, formando blocos ou "teclas", que foram posteriormente preenchidas por depósitos flúvio-marinhos. A evolução estrutural da Bacia PE-PB foi estudada, entre outros autores, por RAND $(76,78)$, subdividindo-a em seis sub-bacias: Cabo, Olinda, Alhandra, Mariri, Canguaretama e Natal. De acordo com os estudos de Mabesone e seus colaboradores, 1991, a subbacia Cabo pertence à Bacia Sergipe-Alagoas e as sub-bacias Canguaratema e Natal "parecem pertencer à continuação sub-oriental da Bacia Potiguar. Dessa forma, as três sub-bacias de estrutura homoclinal denominadas Olinda-Alhandra-Mariri, localizadas entre Recife e João Pessoa, pertenceriam à clássica Bacia sedimentar costeira Pernambuco-Paraíba.

A área de estudo localiza-se na subbacia Olinda que se estende entre o lineamento de Pernambuco e a falha de Goiana, abrangendo uma porção da Bacia e porção do embasamento cristalino da borda oeste da mesma, ver mapa geológico em anexo, figura 4.

Nesta área encontram-se depositados sobre o embasamento cristalino, sedimentos Cretácicos-Terciários que são parcialmente recobertos pelos sedimentos Plio-Pleistcênicos da Formação Barreiras e por sedimentos recentes Quaternários de origens diversas.

Inicialmente houve deposição de sedimentos em ambiente fluvial de baixa sinuosidade até meandrante. Após rápida transgressão marinha, inundando a maior parte da faixa costeira, acompanhada de ressurgência, ocorreu a deposição de fosfato em lugares favoráveis. Seguiram períodos regressivos oscilatórios que se completou no começo do Eoceno. O pacote sedimentar compõe-se portanto de uma seqüência clástica inferior, Formações Beberibe e Itamaracá, e uma seqüência carbonática superior (Gramame e Maria Farinha), MABE- 
SONE,1991. As formações Beberibe e Itamaracá são mais comumente designadas entre os hidrogeólogos por Formação Beberibe superior e Beberibe Inferiror, respectivamente.

Deve-se ressaltar que em função do intenso intemperismo, por vezes torna-se difícil distinguir, em superfície, os sedimentos arenosos da Formação Beberibe e da Formação Barreiras.

\section{Formação Beberibe (Beberibe Inferior)}

Trata-se de arenitos continentais friáveis, avermelhados, marrom ou creme, quartzosos de granulações grosseira a fina, às vezes conglomerático, com matriz microclástica, e intercalações de siltitos e folheIhos. Os grãos arenosos são angulosos a subangulosos, com esfericidade relativamente alta e seleção fraca a má. Devido ao intemperismo profundo não se distingue estruturas sedimentares. Nas amostras de calha, em geral são descritos como material arenoso ou arenitos de grãos angulosos e irregulares, de cor esbranquiçado, creme a cinza, marrom claro ou aroseado, intercalados com argila vermelha, argila escura ou ainda argila de cor verde. Há referências sobre a presença de quartzo enfumaçado, feldspatos e minerais escuros, por vezes denominados de afrisita, nas porções basais, e ocorrência de forte diagênese, principalmente no topo.O Ambiente de sedimentação provável corresponde ao fluvial, em largas planícies aluviais.

\section{Formação Itamaracá}

Trata-se de arenitos bem selecionados, duros, compactos, com cimento calcífero e calcarenitos que ocorrem principalmente em subsuperfície. De acordo com MACIEL, 1981, estes sedimentos foram depositados em ambiente de Plataforma interna tipo lagunar, caracterizado por águas rasas e tranqüilas. Nas amostras de calha, esta formação costuma ser descrita como arenitos levemente a muito calcíferos de cor creme, cinza ou cinza esbranquiçado, apresentando intercalações de argila amarela ou argila esverdeada e por vezes de calcário compacto. É comum a presença de caulim e em alguns poços verificou-se a presença de forte diagênese, principalmente mais próximo ao topo.

A espessura do conjunto Beberibe/Itamaracá é variável, aumentando de Oeste para Leste, havendo ainda uma ten12 dência de redução no sentido norte-sul, apresentando espessura média de 180m , podendo atingir $320 \mathrm{~m}$ próximo ao litoral e apresentando valores em torno de $250 \mathrm{~m}$ entre Olinda e Itamaracá, (COMPESA/CPRM, 1978).

De acordo com COMPESA/CPRM, 1978, a separação entre as duas formações acima citadas ocorre em geral por uma camada argilosa ou síltica de mais ou menos $10 \mathrm{~m}$, podendo por vezes estar ausente.

Em alguns perfis litológicos encontram-se descritos níveis de arenitos calcíferos intercalados com níveis de arenitos não calcíferos, indicando uma interdigitação entre a formação Beberibe e Itamaracá.

\section{Formação Gramame/Maria Farinha}

A Formação Gramame é formada por sedimentos carbonatados, calcilutitos, calcarenitos, calciruditos, de cor original cinza e cor aflorante creme. Na base dessa seqüência em geral encontram-se arenitos calcíferos que gradam para calcários arenosos e a camada de fosfato, culminando no topo com calcários dolomíticos, argilas calcáreas e margas muito fossilíferos. A passagem da Formação Itamaracá para a Gramame pode ser gradativa ocorrendo por vezes intercalações calcáreas no topo da seqüência. O ambiente de deposição desses sedimentos segundo RODRIGUES, 1983, é do tipo marinho de águas quentes, calmas e pouco profundas.

A espessura média é de $30-40 \mathrm{~m}$, com valores máximos de $70 \mathrm{~m}$, sendo que mais ao norte pode atingir mais de $100 \mathrm{~m}$.

A Formação Maria Farinha embora constituindo uma unidade estratigráfica individualizada em termos de conteúdo faunístico, tem características litológicas e modo de ocorrência idênticos ao da Formação Gramame. Segundo OLIVEIRA, 1978, o ambiente de deposição dessa formação é marinho na fase regressiva. Nos perfis litológicos dos poços tubulares é praticamente impossível diferenciar os carbonatos do Gramame dos carbonatos da Formação Maria Farinha. Nas amostras de calha descritas para formação dos perfis litológicos, em geral descreve-se estes carbonatos como Calcários, Margas, calcários argilosos, calcários compactos e calcário laminado de cor cinza a creme, por vezes apresentando arenito calcífero no topo.

\section{Formação Barreiras}


Trata-se de sedimentos afossilíferos, incoerentes de coloração variada granulometricamente diversificados, constituídos por areias quartzosas a subarcosianas de coloração creme, medianamente selecionadas, com aspecto maciço, ocorrendo na base níveis endurecidos de ferro que impermeabilizam as areias cremes e podem formar fontes nos períodos chuvosos ao longo dos cortes de estrada; e areias quartzosas a subarcosianas com cores vivas variando entre alaranjado, vermelho e roxo, apresentando grande porcentagem de pseudomatriz argilosa e geralmente associadas às seguintes formações pelíticas: argilas maciças e siltes, de cores variadas, predominando a caulinita, diamictitos, com baixa densidade de cascalhos/seixos com matriz argilo-arenosa avermelhada que suporta fragmentos sub-angulosos de quartzo na dimensão cascalho e mais raramente, seixos. Nas amostras de calha, em geral, esses sedimentos são descritos como arenito argiloso ou argila cinza plástica, argila amarelada e argila avermelhada.

Foram identificadas nesta formação fácies fluviais associadas a leques aluviais e planícies flúvio-lagunares, (ALHEIROS \& LIMA FILHO, 1991)

\section{Depósitos de Sedimentos Recentes}

Trata-se de sedimentos de origens diversas como aluviões, sedimentos de praia, terraços marinhos Holocênicos e Pleistocênicos, depósitos de mangues e flúvio-lagunares. São sedimentos incoerentes areias variadas, argilas, limos e vasas que recobrem os sedimentos da Bacia PE-PB. Possuem em média $20 \mathrm{~m}$ de espessura podendo chegar a $50 \mathrm{~m}$. Nas amostras de calha dos perfis litológicos estes sedimentos são em geral descritos como areias inconsolidadas de cor creme a esbranquiçada e granulometria de fina a média, sendo que em poços mais rasos torna-se bastante difícil diferencia-las das formações subjacentes.

\section{Substrato Cristalino}

O embasamento cristalino da área denomina-se Zona Transversal ou Pajeú-Paraíba, e está representado por rochas granitizadas dos mais variados tipos texturais, predominando migmatitos, de composição predominantemente granodiorítica com paleossoma anfibolítico e neossoma quartzo- feldspático, ocorrendo freqüentemente granitizados com inclusão de corpos granitizados. As estruturas estão dispostas diagonalmente à direção N-S da linha da costa .

\section{ANÁLISE DOS PERFIS E DISCUSSÕES}

Conforme já mencionado anteriormente foram elaborados oito perfis geológicos, sendo seis deles no sentido Leste/Oeste, cortando transversalmente a direção das camadas e denominados de Perfil 1, 2, 3, 4, 5 e 6, e dois deles no sentido Norte/Sul na mesma direção das camadas, denominados de Perfil 7 e Perfil 8, ver figuras 4 a 11, em anexo. Foram utilizados para confecção dos perfis geológicos um total de 116 poços.

A escolha da localização dos perfis em mapa deve-se a dois fatores: Melhor visualização dos pacotes sedimentares e existência e escolha dos poços mais confiáveis, quanto à localização e segurança dos dados. Os perfis 1 a 6 representam melhor 0 comportamento das diferentes litologias depositadas ao longo do homoclinal, pois cortam perpendicularmente a direção das camadas e, os perfis 7 e 8 pretendem visualizar a variação da geometria dos pacotes sedimentares de sul para norte. Os poços considerados mais confiáveis, são aqueles que foram posicionados por GPS, tal como os poços da COMPESA e aqueles cuja localização pode ser confirmada pelo endereço dos mesmos, a exemplo dos poços presentes em instituições públicas e privadas de localização conhecida como penitenciárias, manicômios, indústrias, conjuntos habitacionais, entre outros.

A elaboração dos perfis geológicos foi feita utilizando-se as seguintes ferramentas: descrições dos perfis litológicos dos poços de abastecimento de água e alguns piezômetros, análise dos mapas geológicos da área e experiência de campo.

A análise dos perfis elaborados permite tecer as seguintes considerações:

- Os pacotes de sedimentos possuem maior espessura quanto mais próximos estiverem da linha de costa, confirmando a estrutura homoclinal, apresentando por vezes pequenas variações na dedeclividade.

- Os sedimentos das formações Beberibe, Itamaracá e Gramame/Maria Farinha, sofreram uma série de falhamentos no sentido NE, SW e NS, prevalecendo as pri- 
meiras. Foi considerada, para melhor composição dos perfis analisados, a existência de outras falhas além daquelas mapeadas por ALHEIROS, 1991, o que, caso sejam comprovadas evidenciariam que a região tenha sofrido maiores esforços tectônicos, resultando em uma série de blocos.

- Não foi possível constatar a tendência de redução da espessura dos sedimentos das Formações Beberibe/Itamaracá no sentido sul-norte

- Na parte basal da formação Beberibe encontra-se por vezes níveis conglomeráticos ou ainda material argiloso plástico que aparentemente pode ser resultante de manto intempérico do embasamento cristalino. Estes níveis podem ser um bom indicativo da proximidade do embasamento cristalino, mas nem sempre ocorrem.

- Há poços onde ocorrem intercalações de arenitos calcíferos com arenitos não calcíferos, das formações Beberibe e Itamaracá, o que pode evidenciar interdigitações dessas duas formações, conforme podem ser vistas nos perfis 1 e 3 , sendo ainda possível ocorrer tal interdigitação com maior freqüência, mas não ter sido detectado pelas amostras de calha.

- Fica evidenciado nos perfis, que é comum a identificação da amostra de calha como arenitos não calcíferos, pertencentes à formação Beberibe, sendo que seria mais coerente do ponto de vista da geologia, identificá-los como pertencentes à formação Itamaracá (calcíferos). A explicação para este fato pode ser a não utilização, por parte do amostrador, de ácido para identificar o componente carbonático das amostras, o que pode acarretar em conseqüências graves para a parte construtiva dos poços pois nesse caso não será possível isolar a captação de água dos níveis não calcíferos das águas mais duras dos níveis calcíferos, comprometendo assim a qualidade da água do poço.

- A ocorrência de níveis não calcíferos identificados nas amostras de calha como níveis calcíferos, também pode ocorrer em função de contaminação das amostras das partes mais inferiores do poço pela amostra das partes mais superiores.

- A formação Itamaracá, em alguns poços, encontra-se intercalada com camadas de argila cinza a argila verde, ou ainda com níveis de calcários.

- Em apenas dois poços do total analisados foi identificada a ocorrência de fosfato, e situavam-se na passagem ente a formação Itamaracá e a parte inferior da Formação Gramame. Segundo Lima FiIho, 2001, estas camadas de fosforitos servem de marco estratigráfico, indicando o início da Formação Gramame. Observa-se contudo, que, apesar de serem de extrema valia para a reconstrução estratigráfica, a identificação do fosfato em amostra de calha é complicada se considerarmos que as espessuras da camada são em geral pequenas (1-8m) e a identificação do material pode ser dificultada em função da mistura com a lama de perfuração e com sedimentos argilosos e calcários.

- Observando-se os perfis 1, 2, 4, 5, 6 e 7, a formação gramame apresenta-se limitada por falhamentos que a coloca em contato lateral com os arenitos da formação Itamaracá.

- Nos blocos altos, relativos às falhas que cortam os sedimentos da bacia, não se observa a presença da Formação Gramame, o que pode sugerir duas hipóteses: ou o calcário gramame ocorre como pequenas ilhas não mapeadas em escala regional, ou todo o calcário teria sido erodido.

- No topo da formação Gramame pode-se encontrar níveis de argila calcífera ou arenito calcífero e camadas de calcário na base, o que pode confundir na descrição do perfil litológico, principalmente se estes níveis estiverem próximo à superfície, ou seja, mascarados por processos intempéricos.

\section{CONCLUSÕES E RECOMENDAÇÕES}

A partir dos perfis geológicos elaborados é possível distinguir três sistemas aqüíferos distintos, possuindo cada um deles importância para o sistema hidráulico do conjunto do pacote sedimentar. O sistema aqüífero Barreiras, que capeia os demais e deve ser melhor investigado no sentido, principalmente de identificar as suas áreas de recarga, o sistema cárstico, que apesar de não ser muito interessante devido a baixa produtividade e má qualidade de suas águas, deve ser melhor estudado no sentido de definir sua interrrelação com o aqüífero 
sotoposto, e o aqüífero intergranular principal, representado pelas formações Beberibe e Itamaracá, que carecem de melhor caracterização, principalmente na porção norte da área estuda.

A análise de amostras de calha para elaboração dos perfis litológicos dos poços mostra-se, ainda que deficiente, de extrema valia para a interpretação da geologia regional e local, no entanto deve ser feita com mais rigor e critérios técnicos, sendo que a experiência do amostrador e seu conhecimento da geologia regional auxiliam na meIhor qualidade do resultado obtido.

Os resultados obtidos nos perfis geológicos comprovam que é possível obter bons resultados utilizando-se desta ferramenta. Contudo, em função das deficiências intrínsecas da amostragem, recomenda-se que sejam aplicados, com mais freqüência, métodos complementares como perfilagem geofísica.

Ressalta-se ainda que quanto menos profundos forem os poços menor a probabilidade de identificarmos com mais segurança a unidade estratigráfica a que pertencem os sedimentos amostrados, pois estará sendo perfurado as porções mais alteradas por processos intempéricos.

Recomenda-se que sejam realizadas campanhas de levantamentos geofísicos para possibilitar maior compreensão dos componentes estruturais.

\section{REFERÊNCIAS BIBLIOGRÁFICAS}

[1] IBGE - Censo Demográfico 2001. Internet, http://www.ibge.gov.br, 05/2001.

[2] OESA - Estudos de reconhecimento e estudos hidrogeológicos para o aproveitamento integrado da região centro-leste da Bacia Potiguar e Bacia Costeira de Pernambuco-Paraíba. SUDENE . Recife. 1975.

[3] COMPESA/CPRM. Diagnóstico Preliminar das condições de exploração de água subterrânea do aqüífero Beberibe área Olinda-Paulista-Itamaracá. Recife, 1978

[4] França, H. P. M. - Plano diretor de abastecimento d'água na Região Metropolitana Norte do Recife. COMPESA. Recife, 1987.

[5] DNPM - Estudo de áreas de proteção de fontes de águas minerais da região norte do
Recife. - In: - Anais do XII Encontro Nacional de Perfuradores de Poços/ IV Simpósio de Hidrogeologia do Nordeste, ABAS, p. 327-336 Olinda, PE, 2001.

[6] França, H. P. M, Neto, B. G. M. V.; André, H. O.; Cirilo, J. A. e Cabral, J. J. S. P. Análise preliminar do comportamento hidrodinâmico e da intrusão marinha no aquiféro beberibe na região metropolitana norte do Recife., p.59-71.In Anais, $1^{\circ}$ Simp. de Hid. do Nordeste,1987.

[7] Montenegro, A. A. A.; França, H. P.; Montenegro, S. M. G. L.; Rolim JR., A. L.; Gênova, D. M.; Cabral, J. J. S. P. - Estudo de recargas no aquífero Beberibe-PE através de modelagem numérica. In: Simpósio de Recursos Hídricos do Nordeste, 1, Recife (PE). Anais... Recife (PE), p. 105-115. nov. 1992.

[8] Costa,W.D.,et al. - Estudo hidrogeológico da Região Metropolitana do Recife.(HIDRREC) Convênio IDRC/UFPE. V. 1Textos, 1998.

[9] Mabesone, J. M. - Revisão geológica da faixa sedimentar costeira de Pernambuco, Paraíba e parte do Rio Grande do Norte. Sedimentos do Grupo Paraíba. Estudos Geológicos. Série B. Recife. vol. 10. 252p.. 71. 1991.

[10] Fortes,F.P.- A tectônica de teclas da Bacia Potiguar. Soc. Bras. Geol., Anais XXXIV Congr.,Goiânia (GO), 3: 11451159.1986.

[11] Rand, H. M.- Estudos geofísicos na faixa litorânea no sul do Recife. Univ. Fed. Pernambuco, Tese livre-Docência,p.112.1976.-

Análise gravimétrica e magnetométrica da estrutura subsurpeficial da faixa costeira do Nordeste brasileiro. Soc. Bras. Geol., Anais XXX Congr.,Recife(PR), 5:p. 2336- 2346. 1978.

[12] Maciel,S.M.S.R. -Contribuição ao estudo das fácies carbonáticas interdigitadas na formação Beberiibe (PEPB).Dissertação.1981. 
[13] Rodrigues,F.F.-Estudo faciológico do calcário Gramame na ilha de Itamaracá (PE). Dissertação.1983.

[14] Oliveira, M.M.M:F.- Estudo faciológico da formação Maria Farinha(PE-PB). Dissertação.1978.

[15] Alheiros,M.M.\& Lima Filho,M.F - Revisão geológica da faixa sedimentar costeira de Pernambuco, Paraíba e parte do Rio Grande do Norte - Sedimentos do Grupo Paraíba. Estudos Geológicos. Série B. Recife. vol. 10. Pag.77-78. 1991.

[16] Lima Filho,M.F.- Marco Estratigráfico nos Arenitos Calcíferos do Campaniano da Bacia Paraíba: Eatratigrafia e significado Paleoambiental. Simpósio de Geologia do Nordeste, Natal (RN).2001.

\section{ANEXOS}

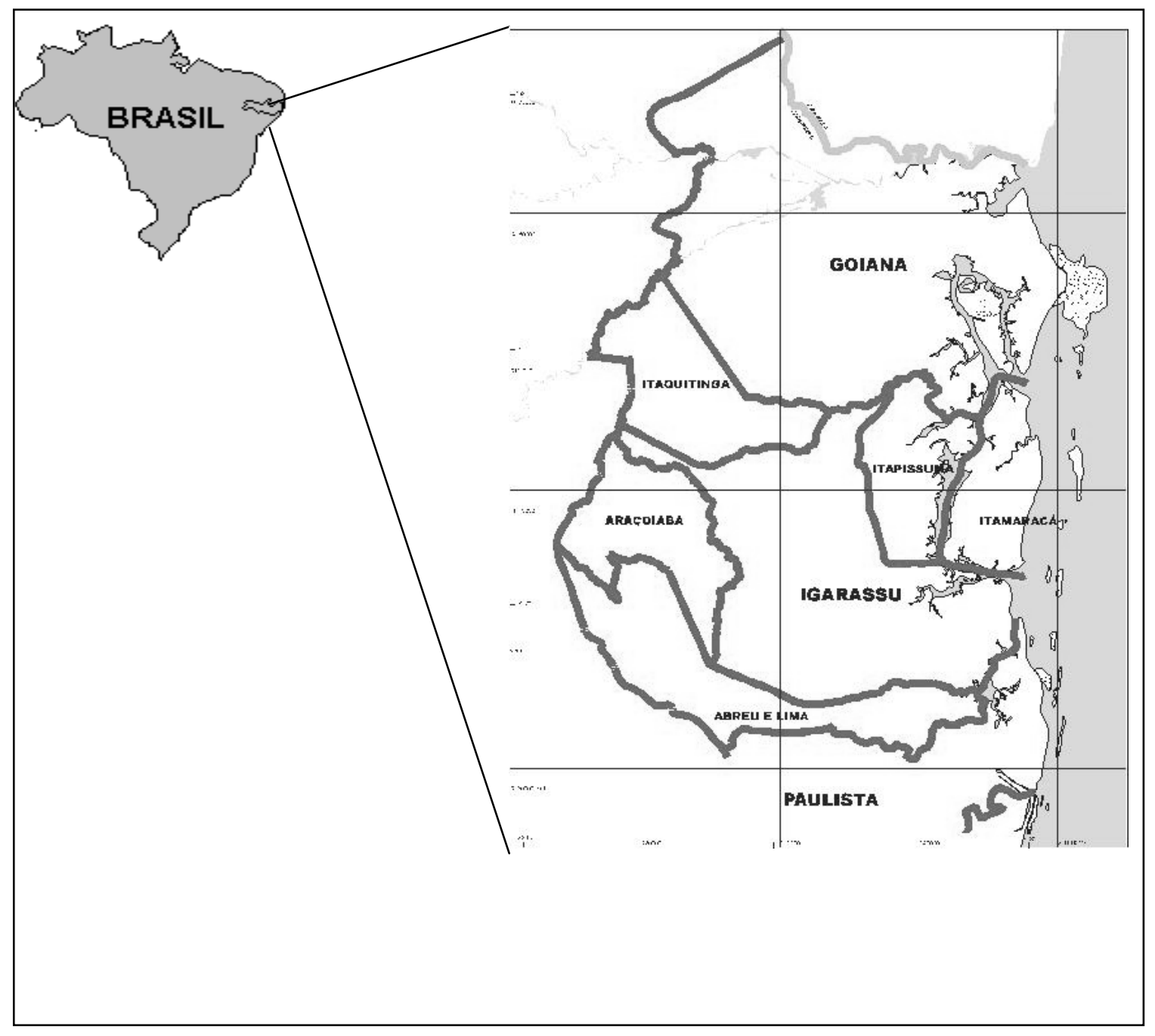

Figura 2 : Mapa de localização da área de estudo.

Fonte: Diagnóstico Sócio Ambiental do Litoral Norte de Pernambuco, CPRH, 2001. 
Rev. Águas Subterrâneas nº 17/ Maio 2003.

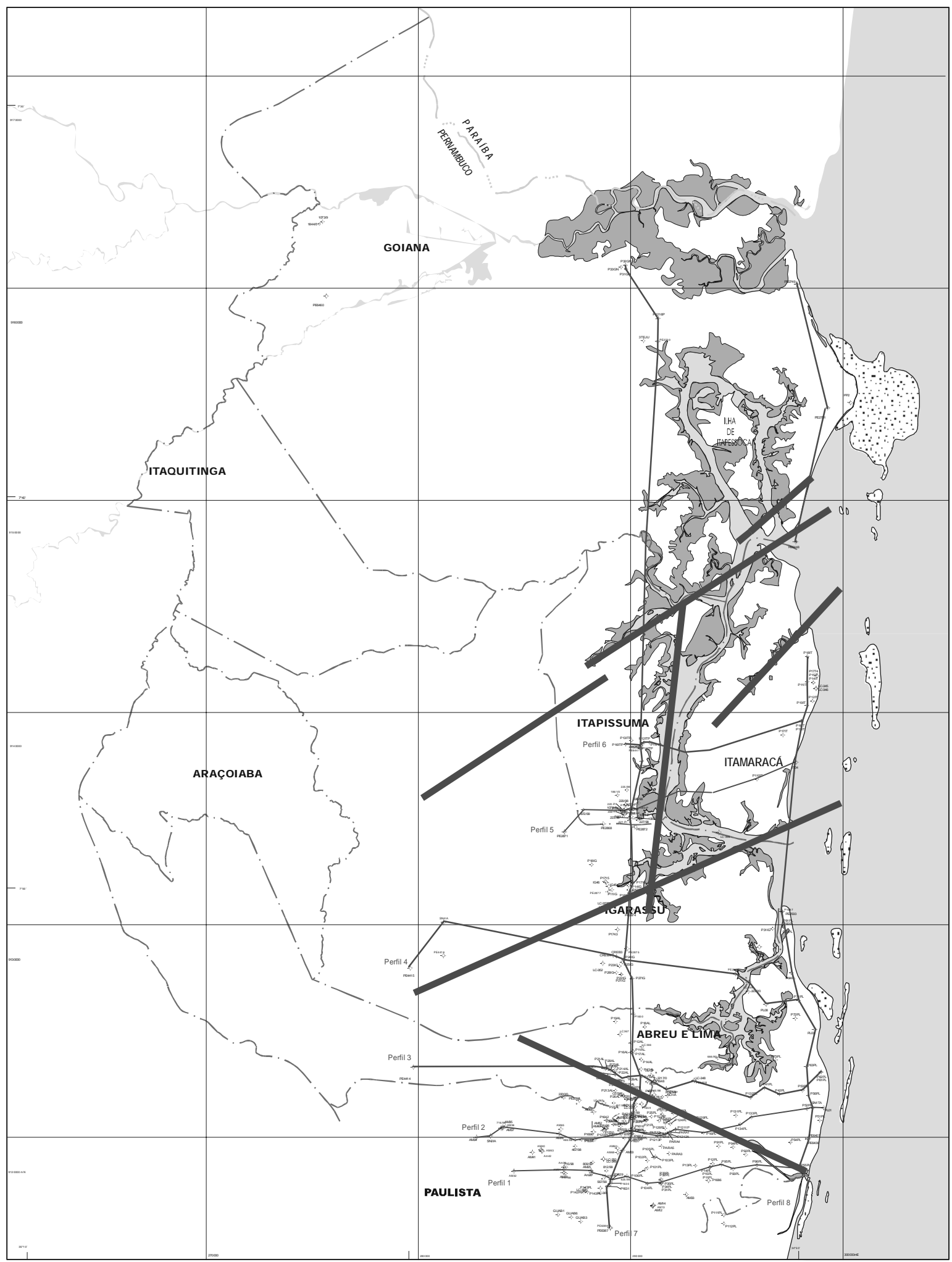

Fifura 3: MAPA DE LOCALIZAÇÃO DOS POÇOS COM PERFIL LITOLÓGICO E CONSTRUTIVO 
Rev. Águas Subterrâneas nํ17/ Maio 2003.

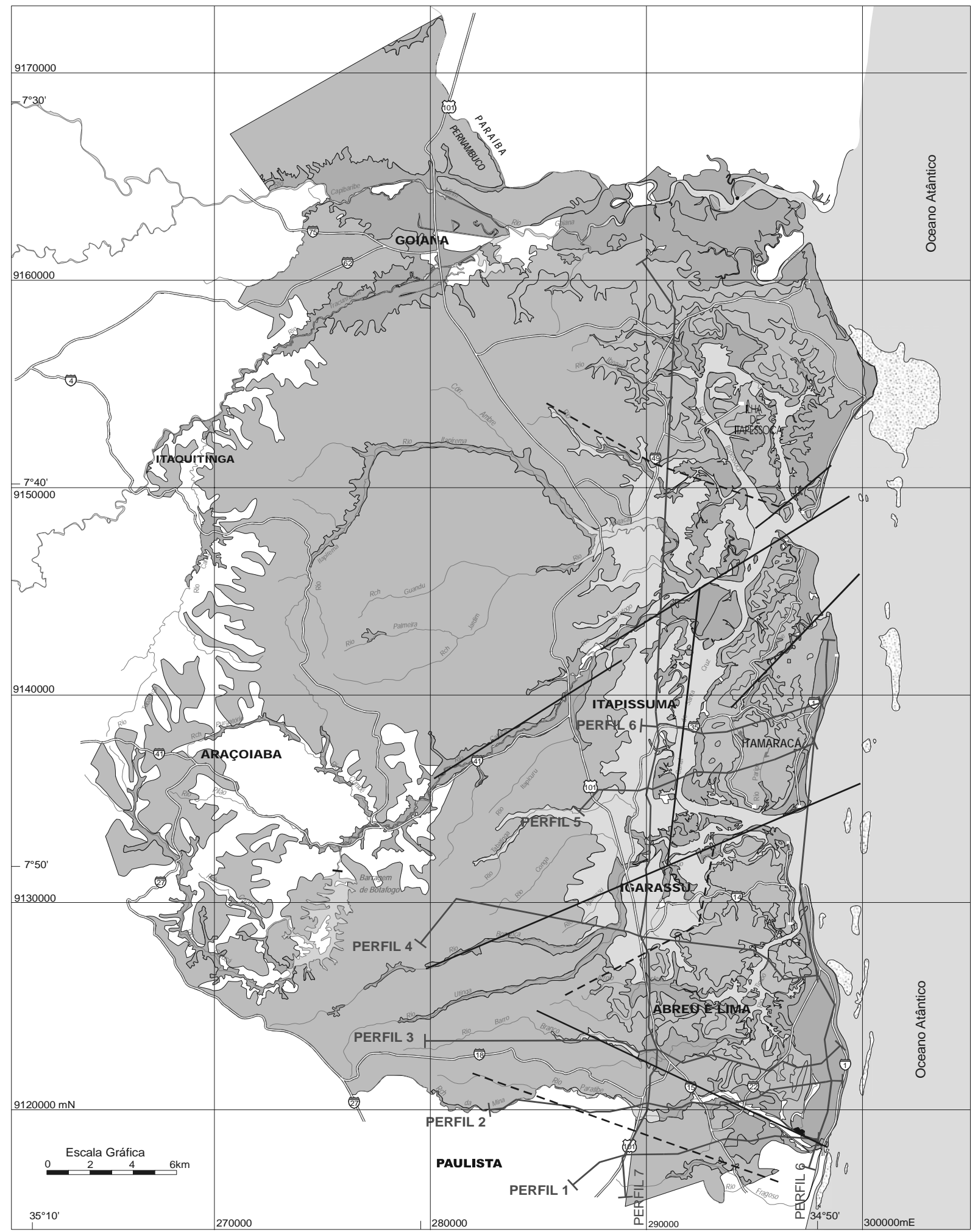

Fonte: UFPE-LGGM, Macrozoneamento Costeiro do Litora Norte de Pernambuco, Folha Itamaracá, 1992. ALHEIROS, Margareth M., Mapa Geológico da Região Metropolitana do Recife, 1998

\section{LEGENDA}

SEDIMENTOS RECENTES (Aluvião, Mangue e Terraços)

SISTEMA BARREIRAS

Falha Geológica
SISTEMA CÁRSTICO (Fm. Gramame/ Fm. Marinha Farinha)

SISTEMA INTERGRANULAR PRINCIPAL

(Fm. Itamaracá/ Fm. Beberibe)

___- Falha Geológica inferida através dos perfis geofógicos 


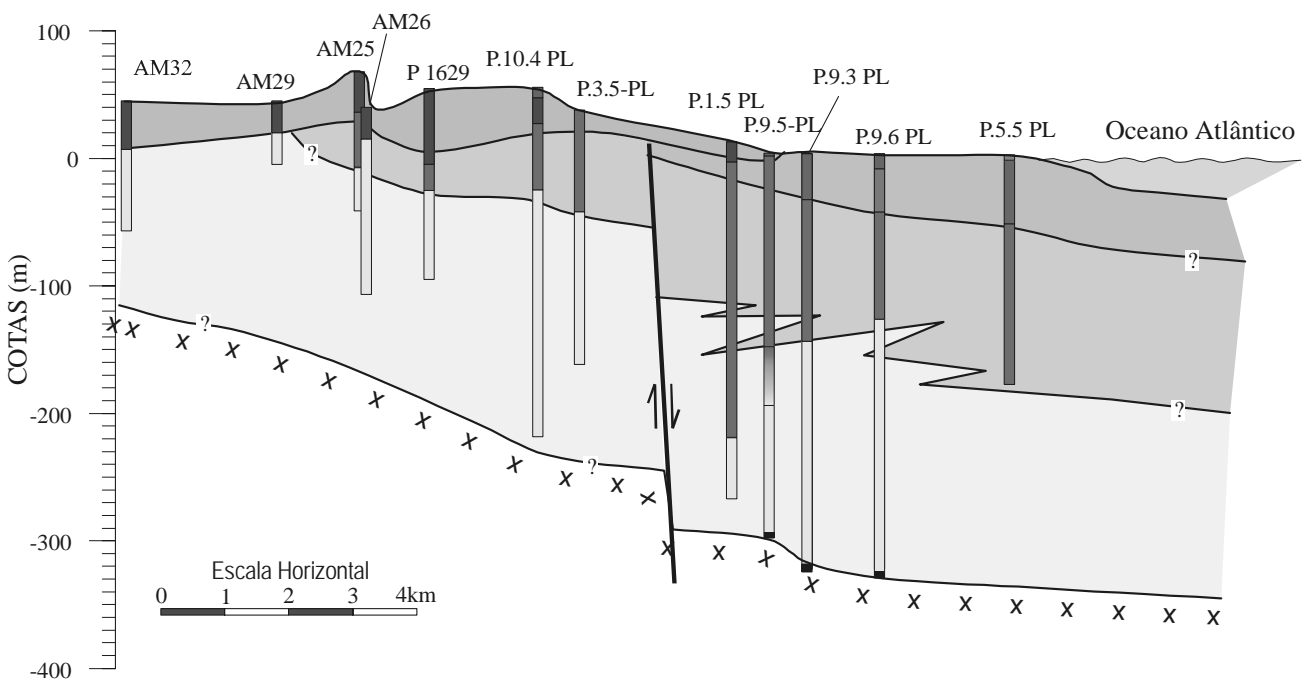

\section{LEGENDA PARA AS SONDAGENS}

Sed. Rec./Aluvioes / mangue

Fm. Barreiras

Fm. Gramame/Maria Farinha

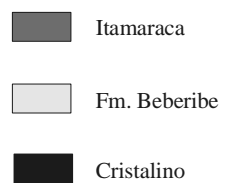

\section{LEGENDA PARA O PERFIL}

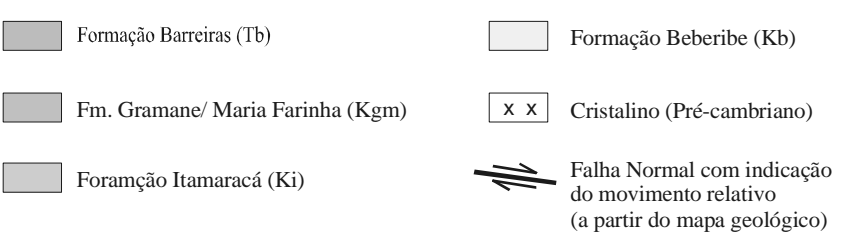

Figura 5 - Perfil 1

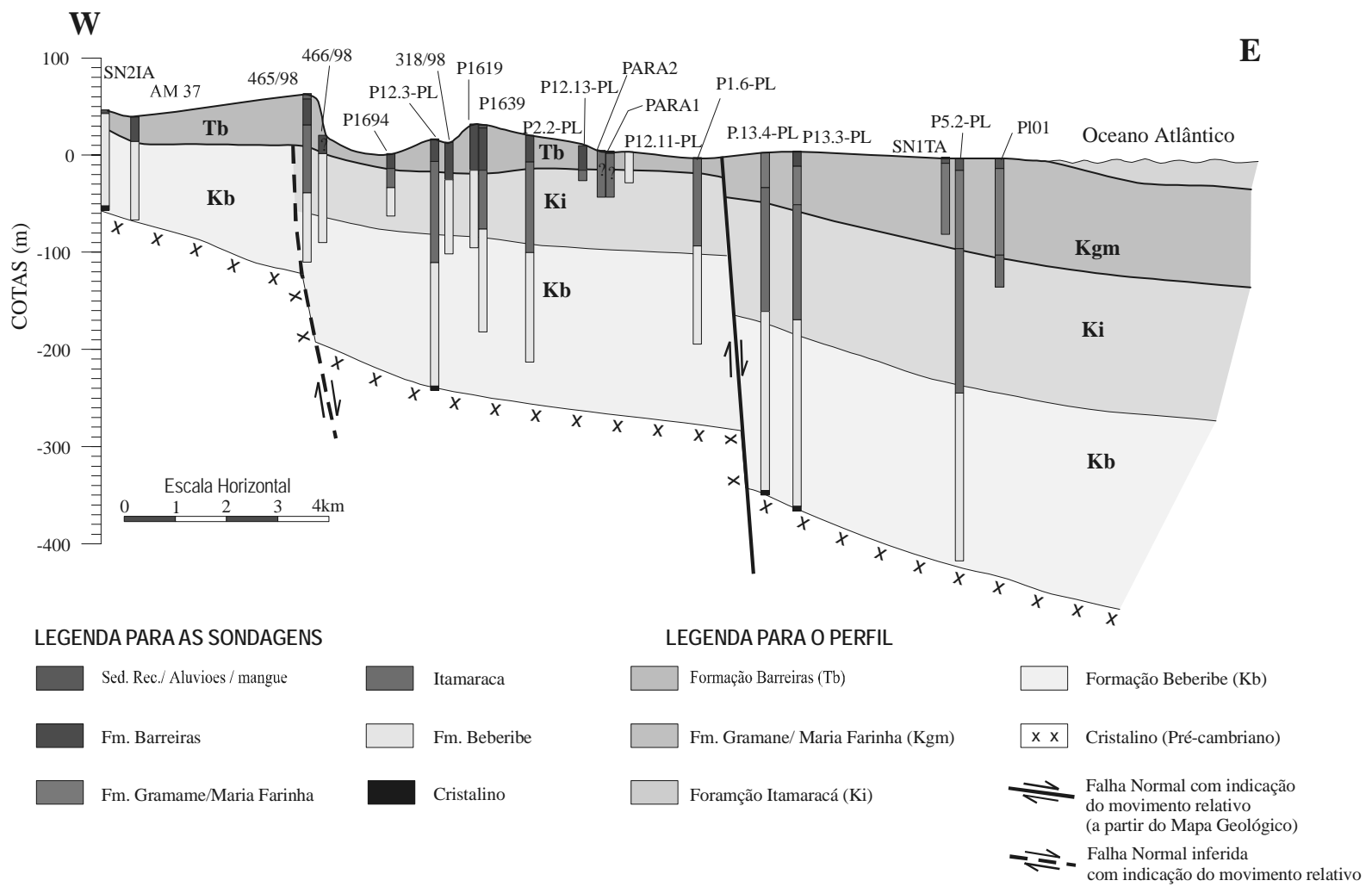


Rev. Águas Subterrâneas nํ17/ Maio 2003.

Figura 6 - Perfil 2

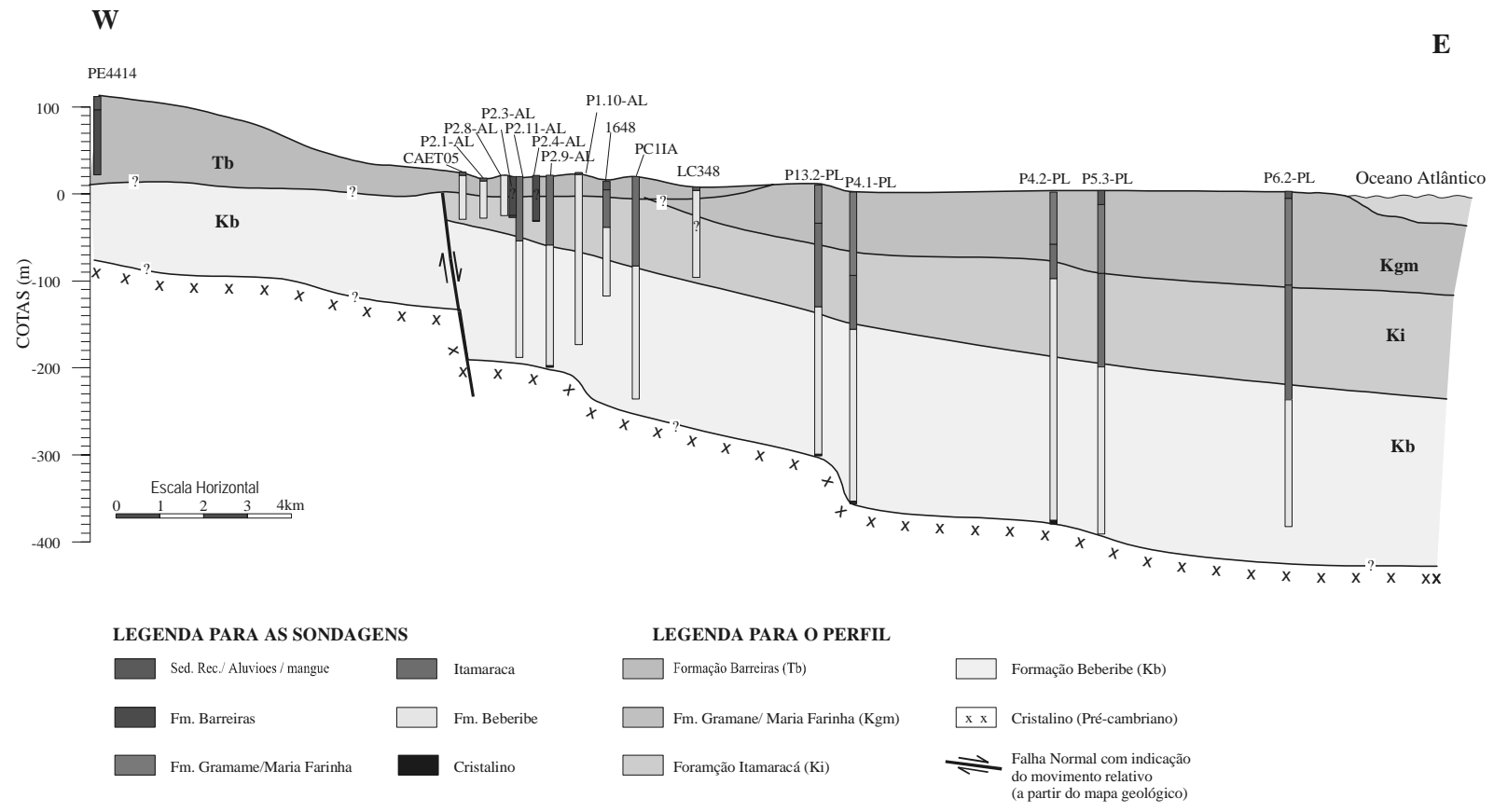

Figura 7 - Perfil 3

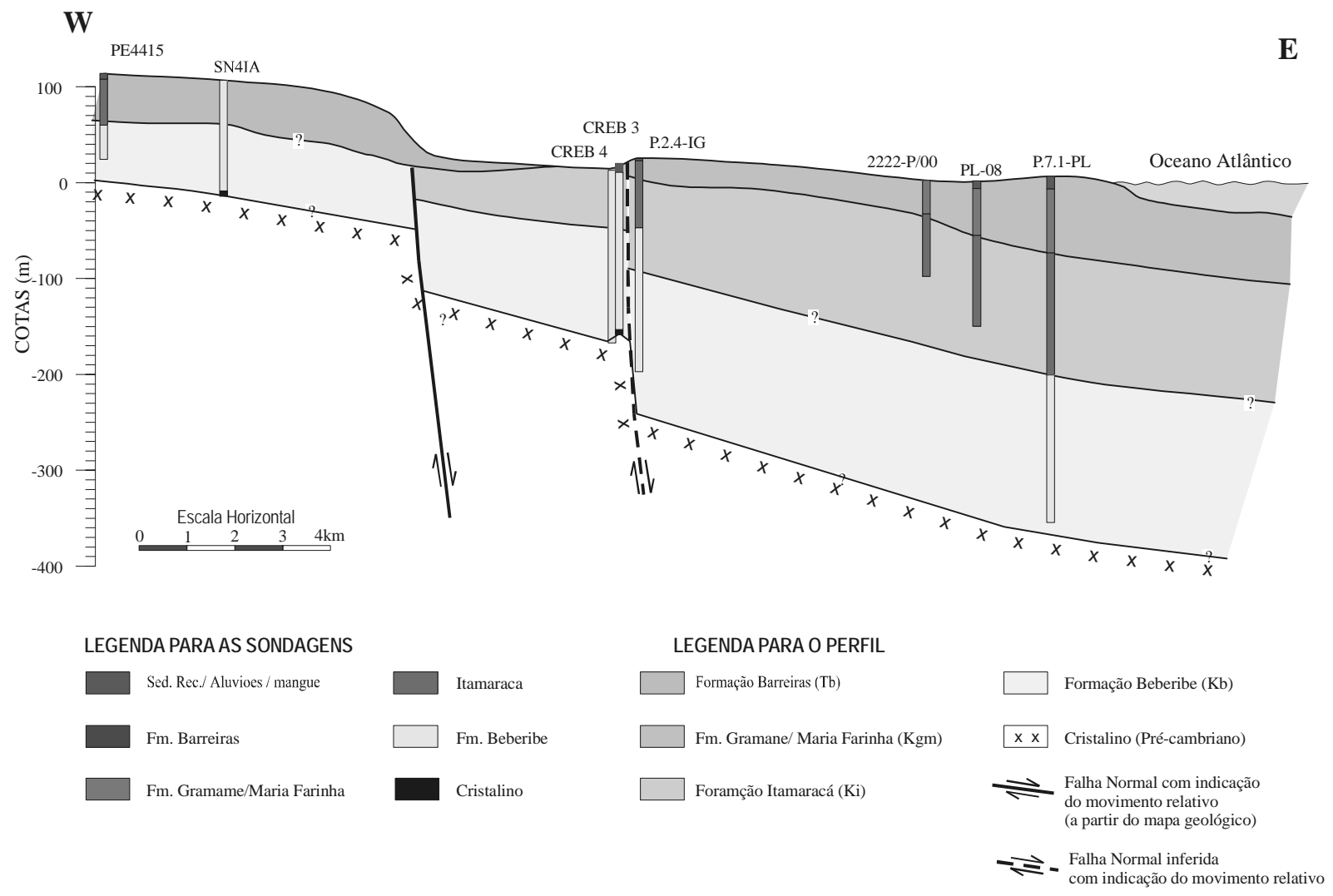

Figura 8 - Perfil 4 
Rev. Águas Subterrâneas nº 17/ Maio 2003.

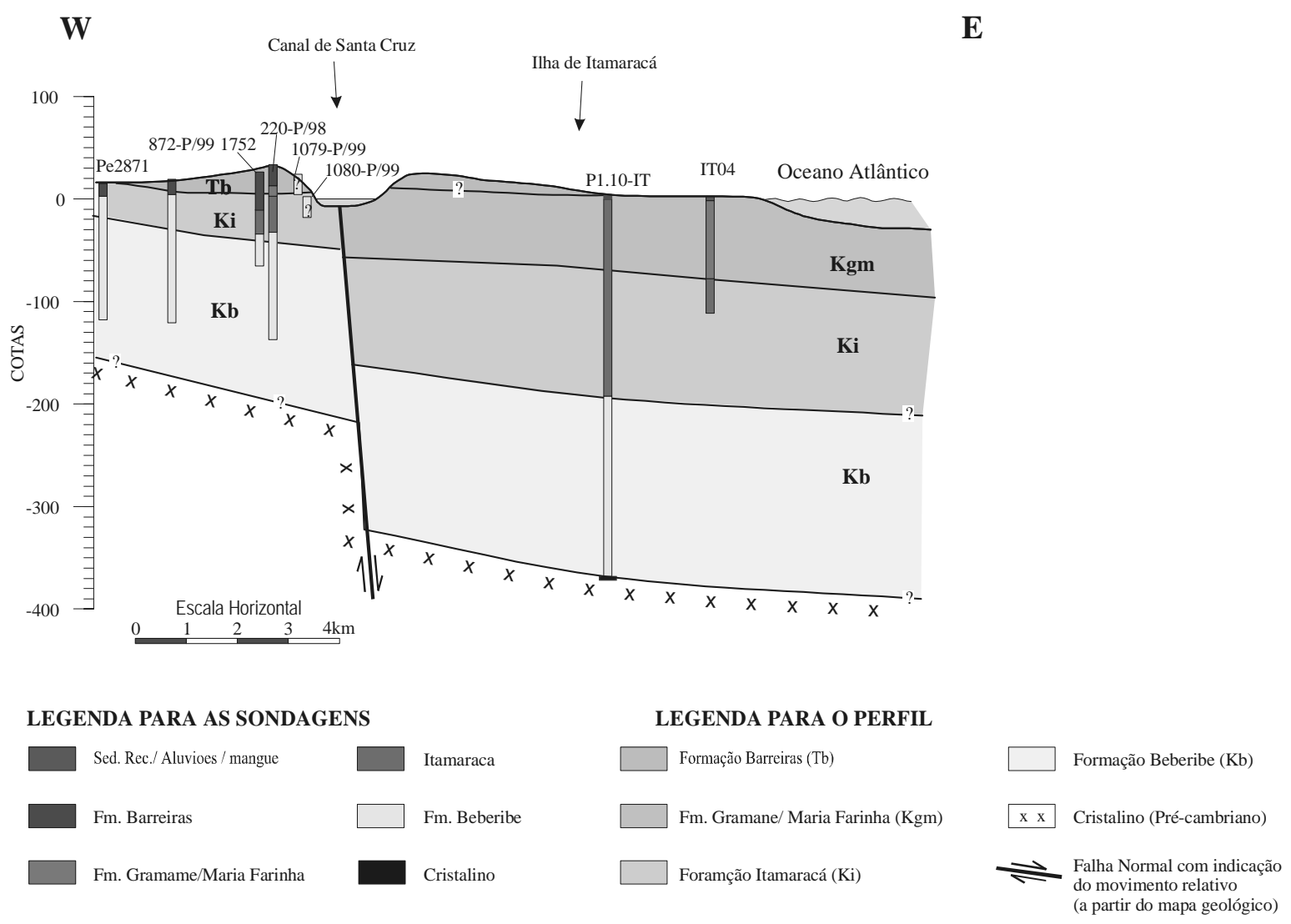

Figura 9 - Perfil 5

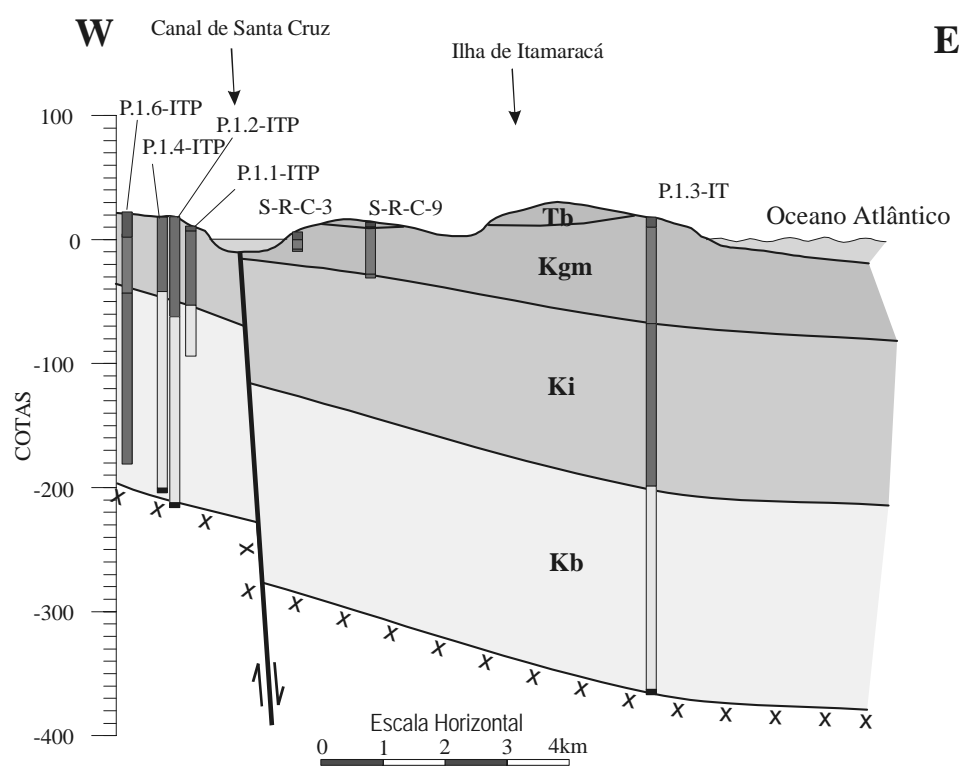

\section{LEGENDA PARA AS SONDAGENS}

Sed. Rec./ Aluvioes / mangue

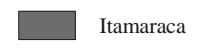

Fm. Barreiras

Fm. Gramame/Maria Farinha

\section{Fm. Beberibe}

Cristalino

\section{LEGENDA PARA O PERFIL}

Formação Barreiras (Tb)

Fm. Gramane/ Maria Farinha (Kgm)

Foramção Itamaracá (Ki) 
Rev. Águas Subterrâneas nํㅜ 17/ Maio 2003.
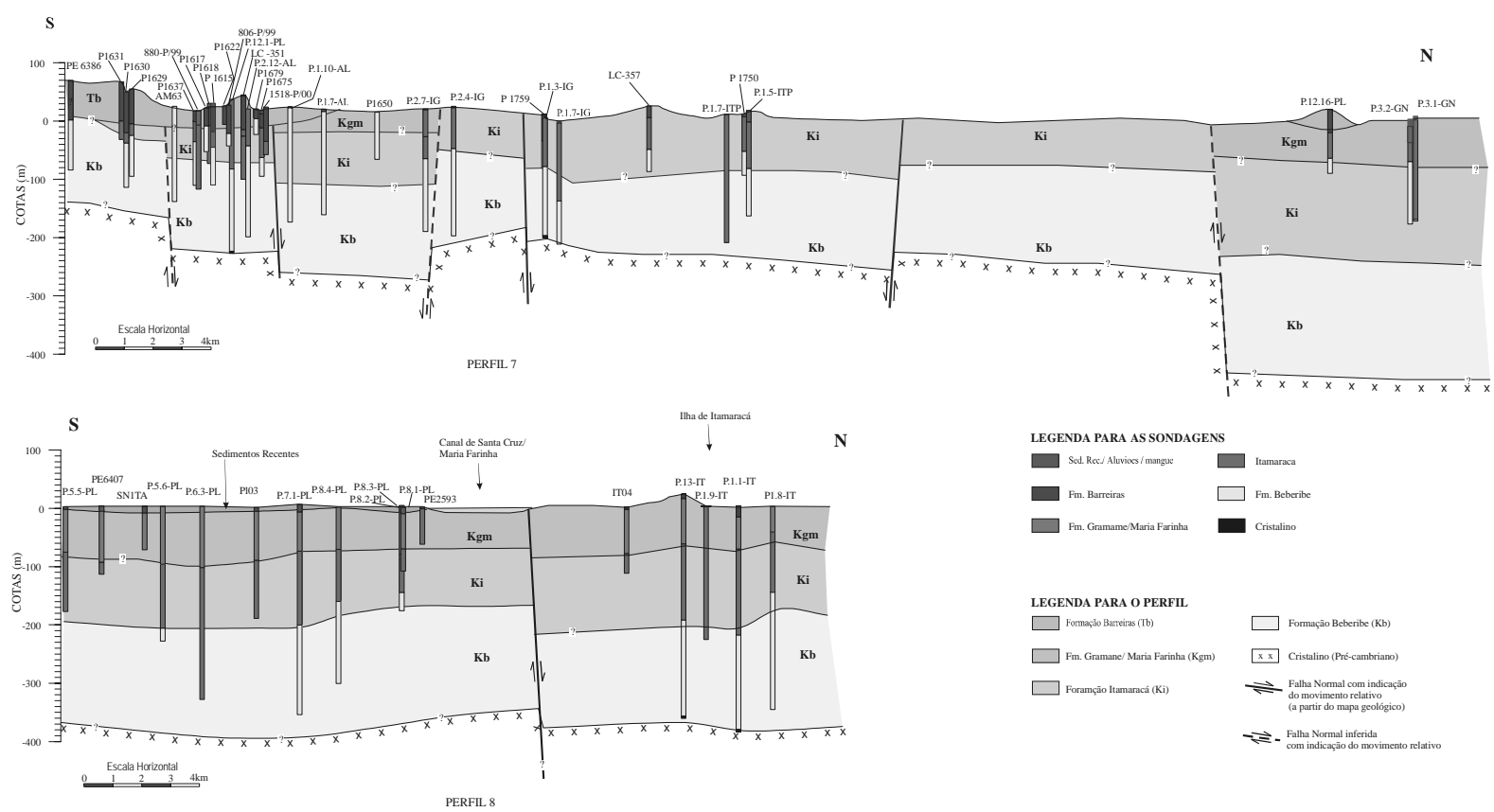

LEGENDA PARA O PERFIL

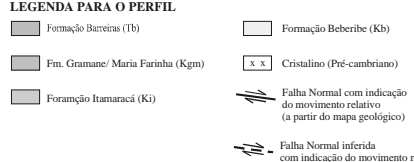

Figura 11 - Perfis 7 e 8 